\title{
Spectrophotometric high-precision seawater pH determination for use in underway measuring systems
}

\author{
S. Aßmann ${ }^{1}$, C. Frank ${ }^{1}$, and A. Körtzinger ${ }^{2}$ \\ ${ }^{1}$ Helmholtz-Zentrum Geesthacht, Institute of Coastal Research, Max-Planck-Str. 1, 21502 Geesthacht, Germany \\ ${ }^{2}$ Leibniz Institute of Marine Sciences, Marine Biogeochemistry, Düsternbrooker Weg 20, 24105 Kiel, Germany \\ Received: 27 May 2011 - Published in Ocean Sci. Discuss.: 14 June 2011 \\ Revised: 14 September 2011 - Accepted: 17 September 2011 - Published: 4 October 2011
}

\begin{abstract}
Autonomous sensors are required for a comprehensive documentation of the changes in the marine carbon system and thus to differentiate between its natural variability and anthropogenic impacts. Spectrophotometric determination of $\mathrm{pH}-\mathrm{a}$ key variable of the seawater carbon system - is particularly suited to achieve precise and drift-free measurements. However, available spectrophotometric instruments are not suitable for integration into automated measurement systems (e.g. FerryBox) since they do not meet the major requirements of reliability, stability, robustness and moderate cost. Here we report on the development and testing of a new indicator-based $\mathrm{pH}$ sensor that meets all of these requirements. This sensor can withstand the rough conditions during long-term deployments on ships of opportunity and is applicable to the open ocean as well as to coastal waters with a complex matrix and highly variable conditions. The sensor uses a high resolution CCD spectrometer as detector connected via optical fibers to a custom-made cuvette designed to reduce the impact of air bubbles. The sample temperature can be precisely adjusted $\left(25^{\circ} \mathrm{C} \pm 0.006^{\circ} \mathrm{C}\right)$ using computer-controlled power supplies and Peltier elements thus avoiding the widely used water bath. The overall setup achieves a measurement frequency of $1 \mathrm{~min}^{-1}$ with a precision of $\pm 0.0007 \mathrm{pH}$ units, an average offset of $+0.0005 \mathrm{pH}$ units to a reference system, and an offset of $+0.0081 \mathrm{pH}$ units to a certified standard buffer. Application of this sensor allows monitoring of seawater $\mathrm{pH}$ in autonomous underway systems, providing a key variable for characterization and understanding of the marine carbon system.
\end{abstract}

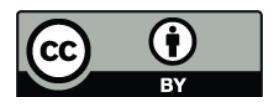

Correspondence to: $\mathrm{S}$. Aßmann (steffen.assmann@hzg.de)

\section{Introduction}

The $\mathrm{pH}$ of seawater is one of the four variables used to analytically determine the parameters of the seawater $\mathrm{CO}_{2}$ system (Millero, 2007). It has been shown that the $\mathrm{pH}$ of the surface ocean is decreasing by about $0.0019 \mathrm{pH}$ units per year (Dore et al., 2009; Feely et al., 2009) as a consequence of $\mathrm{CO}_{2}$ uptake due to the increasing atmospheric $\mathrm{CO}_{2}$ concentration (Sabine et al., 2004). The oceanic sink for anthropogenic $\mathrm{CO}_{2}$ amounts to approx. $41 \%$ (Sabine and Tanhua, 2010) of the entire cumulative emissions. This phenomenon, also known as ocean acidification (Doney et al., 2009), may have significant effects on marine ecosystems (Fabry et al., 2008) and has become a major research area. To adequately document natural variability a high temporal and spatial resolution of high quality $\mathrm{pH}$ measurements is needed. Therefore, there is a large interest to include $\mathrm{CO}_{2}$ system parameters as standard parameters during ship cruises and on monitoring stations. Especially in coastal areas these monitoring devices have to be very robust to withstand rough environmental conditions as well as rapid changes in the composition of the water body.

For the measurement of seawater $\mathrm{pH}$ different approaches are described in the literature. The most promising approach for $\mathrm{pH}$ determination are spectrophotometric measurements employing an indicator dye, refined by Clayton and Byrne (1993). The use of glass electrodes for potentiometric $\mathrm{pH}$ determination of seawater can not be recommended due to the limited accuracy $( \pm 0.01 \mathrm{pH}$ units) of these sensors (SCOR Working Group 75, 1988). However, another promising approach is the application of Durafets (ion sensitive field effect transistor based $\mathrm{pH}$ sensors) tested by Martz et al. (2010).

The spectrophotometric method uses an indicator dye with an appropriate and precisely known $\mathrm{p} K_{\mathrm{a}}$ value and

Published by Copernicus Publications on behalf of the European Geosciences Union. 
acceptable extinction coefficient ratios of the basic and acidic form. The robustness of this method lies in the potential stability of such a system, which relies only on the accurate measurement of salinity and temperature, thereby circumventing all problems associated with the calibration of such a system. It has been realized successfully in various designs and applications. Many designs already focus on in-situ applications like profiling and moorings (Martz et al., 2003; Liu et al., 2006; Nakano et al., 2006; Seidel et al., 2008) and also on underway systems (Bellerby et al., 2002). These instruments measure the $\mathrm{pH}$ at in-situ temperature and thus have to use the thymol blue indicator whose $\mathrm{p} K_{\mathrm{a}}$ value is known over a large temperature range (Zhang and Byrne, 1996). Due to the slight mismatch of the indicator range of thymol blue and of the natural seawater $\mathrm{pH}$ range, this indicator dye is not as well suited for use in coastal waters as m-Cresol Purple (mCP). Liu et al. (2011) specified the $\mathrm{p} K_{\mathrm{a}}$ temperature range of $\mathrm{mCP}$ to a large extent $\left(5^{\circ} \mathrm{C} \leq T \leq 35^{\circ} \mathrm{C}\right)$ which makes it now suitable for in-situ application. However, this specification is only valid for purified $\mathrm{mCP}$ which was not used here. Another approach is to use $\mathrm{mCP}$ and adjust the temperature of the sample to $25^{\circ} \mathrm{C}$ to circumvent the problem of the limited temperature range as demonstrated by Friis et al. (2004). Friis used a water bath to adjust the temperature of the sample and had to cope with all the problems related to maintaining and transporting such a bath.

These designs are not suitable for integration into an automated water measurement system like the FerryBox (Petersen et al., 2003). This system is commonly used in coastal regions which can have large changes in water temperature and a wide range of $\mathrm{pH}$ values due to e.g. high primary production. The FerryBox devices are usually built into ships of opportunity operating under highly varying conditions without user interaction.

The system described here uses $\mathrm{mCP}$ as a $\mathrm{pH}$ indicator and finely adjusts the sample temperature to $25^{\circ} \mathrm{C}$ using Peltier elements. The system design is simple and has proven to be very robust against changing environmental conditions as well as changes in the water composition and sediment load. Additionally, the non-linearity of the CCD spectrometer is compensated using a technique similar to that of Salim et al. (2011).

\section{Theory}

Three different seawater $\mathrm{pH}$ scales are described in the literature, the "free", "total" and "seawater" scale. The difference between these scales refers to the seawater model employed. Details can be found in Dickson (1984) and Zeebe and WolfGladrow (2001). Measured pH values on one scale can be recalculated to another scale under certain boundary conditions. In this study the total scale is used since the applied equilibrium constants and the $\mathrm{pH}$ value of the certified reference material (CRM) were determined on this scale. The formal definition of the total scale is given by the following equations:

$\left[\mathrm{H}^{+}\right]_{\mathrm{T}}=\left[\mathrm{H}^{+}\right]_{\mathrm{F}}\left(1+\frac{S_{\mathrm{T}}}{K_{\mathrm{S}}}\right)$,

$\left[\mathrm{H}^{+}\right]_{\mathrm{T}} \approx\left[\mathrm{H}^{+}\right]_{\mathrm{F}}+\left[\mathrm{HSO}_{4}^{-}\right]$,

where $S_{\mathrm{T}}$ is the total sulfate concentration, $K_{\mathrm{S}}$ is the second dissociation constant of sulfuric acid and $\left[\mathrm{HSO}_{4}^{-}\right]$represents the hydrogen sulfate ion concentration.

Spectrophotometric $\mathrm{pH}$ determination is based on the second dissociation reaction of the diprotic sulfonephthalein indicator dye meta-Cresol Purple,

$\mathrm{HI}^{-} \stackrel{\mathrm{p} K_{\mathrm{a}}^{\prime}}{\rightleftharpoons} \mathrm{I}^{2-}+\mathrm{H}^{+}$

where $\mathrm{HI}^{-}$and $\mathrm{I}^{2-}$ are the protonated and unprotonated forms of the two indicator species and $\mathrm{p} K_{\mathrm{a}}^{\prime}$ is the second apparent dissociation constant of the dye. The indicator $\mathrm{mCP}$ was chosen due to the good match of the indicator $\mathrm{pH}$ range 7.4 to 9.0 (Milne, 2005) and the $\mathrm{pH}$ range 7.5 to 8.5 present in natural seawater (Raven et al., 2005). The $\mathrm{p} K_{\mathrm{a}}^{\prime}$ is a function of temperature $T$ and salinity $S$,

$\mathrm{p} K_{\mathrm{a}}^{\prime}=\frac{1245.69}{T / \mathrm{K}}+3.8275+0.00211(35-S)$

and valid for temperatures in the range from $293 \mathrm{~K}$ to $303 \mathrm{~K}$ and salinities from 30 to 37 (Clayton and Byrne, 1993). The correction of the $\mathrm{p} K_{\mathrm{a}}^{\prime}$ suggested by DelValls and Dickson (1998) was disregarded in this study. We refer to current literature (Dickson et al., 2007) where this correction is not taken into account.

The $\mathrm{pH}$ of seawater can be calculated using:

$$
\begin{aligned}
\mathrm{pH}_{\mathrm{T}} & =-\log _{10}\left[\mathrm{H}^{+}\right]_{\mathrm{T}} \\
& =\mathrm{p} K_{\mathrm{a}}^{\prime}+\log _{10}\left(\frac{R-e_{1}}{e_{2}-R \cdot e_{3}}\right),
\end{aligned}
$$

where $R$ is the absorbance ratio $A_{578} / A_{434}$ corresponding to the peak maximum wavelengths $578 \mathrm{~nm}$ and $434 \mathrm{~nm}$ of the indicator species $\mathrm{I}^{2-}$ and $\mathrm{HI}^{-} . e_{i}$ are the ratios of the molar extinction coefficients $\varepsilon$ (Clayton and Byrne, 1993) as defined below:

$$
\begin{aligned}
& e_{1}=\frac{\varepsilon_{578}^{\mathrm{HI}^{-}}}{\varepsilon_{434}^{\mathrm{HI}}}, \quad e_{2}=\frac{\varepsilon_{578}^{\mathrm{I}^{-2}}}{\varepsilon_{434}^{\mathrm{HI}^{-}}}, \quad e_{3}=\frac{\varepsilon_{434}^{\mathrm{I}^{2-}}}{\varepsilon_{434}^{\mathrm{HI}^{-}}}, \\
& e_{1}=0.00691, \quad e_{2}=2.2220, \quad e_{3}=0.1331 \text {. }
\end{aligned}
$$

To calculate the absorbance ratio $R$, the raw spectrophotometric data are corrected for stray light and non-linearity of the CCD detector/AD-converter (see Sect. 3.5). Furthermore the $\mathrm{pH}$ perturbation resulting from the addition of indicator dye solution is corrected as presented in Sect. 3.5. 


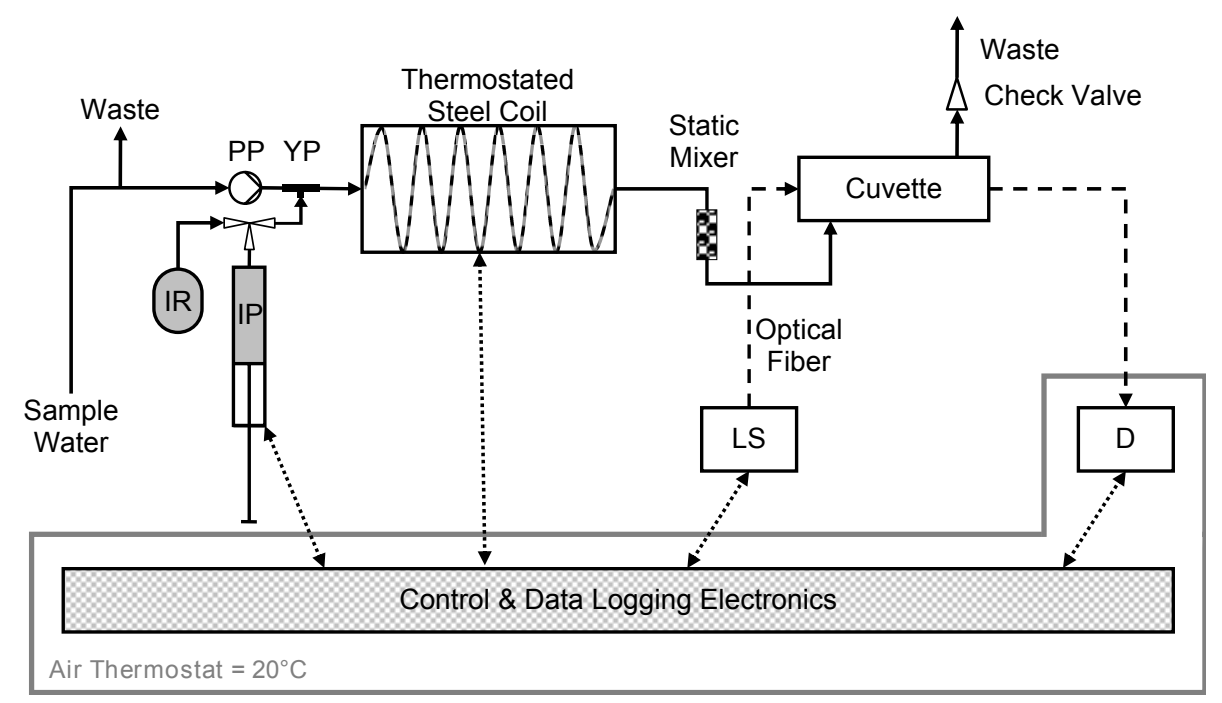

Fig. 1. Overview of the spectrophotometric pH system. IR: Indicator Reservoir, PP: Peristaltic Pump, IP: Indicator Pump, YP: Y-piece, LS: Light Source, D: Detector. The steel coil is embedded in an aluminum body providing a temperature regulation of the continuous flow in the cuvette to $25^{\circ} \mathrm{C} \pm 0.006^{\circ} \mathrm{C}(1 \sigma)$. The cuvette is isolated with polystyrene for protection from environmental temperature fluctuations.

Recent publications (Yao et al., 2007; Liu et al., 2011) indicate that the $\mathrm{pH}$ determination has an error of approx. $0.01 \mathrm{pH}$ units using an indicator dye directly obtained from the manufacturers without further purification. New constants are available for purified $\mathrm{mCP}$, which is not yet commercially available. It would be questionable to use constants for pure $\mathrm{mCP}$ while measuring with impure $\mathrm{mCP}$. Clayton and Byrne (1993) also used an impure indicator dye for their calibration. These constants are used here.

\section{Materials and methods}

\subsection{System design and sample handling}

The setup presented here is a bench-top system which consists of a syringe pump, a heat exchange system, a cuvette composed of polyethylene terephthalate (PET), a control and data logging unit, and the optical system (Fig. 1).

The liquid handling is performed by a peristaltic pump (ISMATEC, ISM597D) to ensure a continuous stable flow and a syringe pump (Hamilton, PSD/2) for accurate injection of the indicator. All tubing, which is in contact with sample water, has at least $1 \mathrm{~mm}$ i.d. preventing obstruction of the sample flow due to particles (e.g. in coastal waters). A gas tight plastic bag with an aluminum coating (Calibrated Instruments, Cali5Bond) is used as the indicator reservoir (IR). The indicator stock solution consists of $2 \mathrm{mmol} \mathrm{kg}$-soln $^{-1} \mathrm{mCP}$ sodium salt (Sigma Aldrich, 211761) in a $0.7 \mathrm{~mol} \mathrm{kg-soln}{ }^{-1} \mathrm{NaCl}$ (Merck, 106404) solution (ionic strength $I=0.7$ ) to keep the equilibrium constants of the carbon system nearly undisturbed. An injection of $112.5 \mu \mathrm{l}$ indicator stock solution by the indicator pump (IP) into the continuous sample flow of approx. $10 \mathrm{ml} \mathrm{min}^{-1}$ results in an

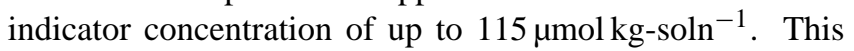
equates to absorbance values up to 0.9 at the isosbestic point of the dye $(487.6 \mathrm{~nm})$ and to absorbance values up to 1.8 at the indicator maxima $(434 \mathrm{~nm}, 578 \mathrm{~nm})$. Although a nonlinear behavior of the absorbance above 1.4 is possible, no such effects were observed here. Mixing of indicator dye and sample is realized by injecting the indicator solution through a tight Y-piece (YP) followed by a static mixer (piece of tubing filled with glass balls). Due to the laminar flow it is very important to place the mixer near to the cuvette to ensure a homogeneous solution in the optical path.

The seawater sample is provided by an automated water measurement system called FerryBox (Petersen et al., 2003) which is fed with a continuous flow of seawater from the clean seawater pump of the vessel. The seawater stream passes a T-piece and ends up in an open outflow to waste. The other end of the T-piece is connected to the peristaltic pump (PP).

After indicator aspiration and injection the sample flows through a stainless steel tube ( $3 \mathrm{~mm}$ o.d.) embedded in an aluminum body which is kept at $25^{\circ} \mathrm{C}$ (heat exchanger). The sample then passes the static mixer and enters the cuvette. The cuvette is made of black PET containing a typical Z-type optical path with an additional interface for a temperature sensor (Fig. 2). This sensor is used to regulate the temperature of the sample in the cuvette and also to correct the $\mathrm{p} K_{\mathrm{a}}^{\prime}$ of $\mathrm{mCP}$. In order to avoid bubble formation, the waste tube ends about $1 \mathrm{~m}$ higher than the outlet of the cuvette thus providing a constant back pressure. An additional check valve was needed to eliminate pressure changes due to the movement of the ship (caused by the swell of the sea). The overall setup 


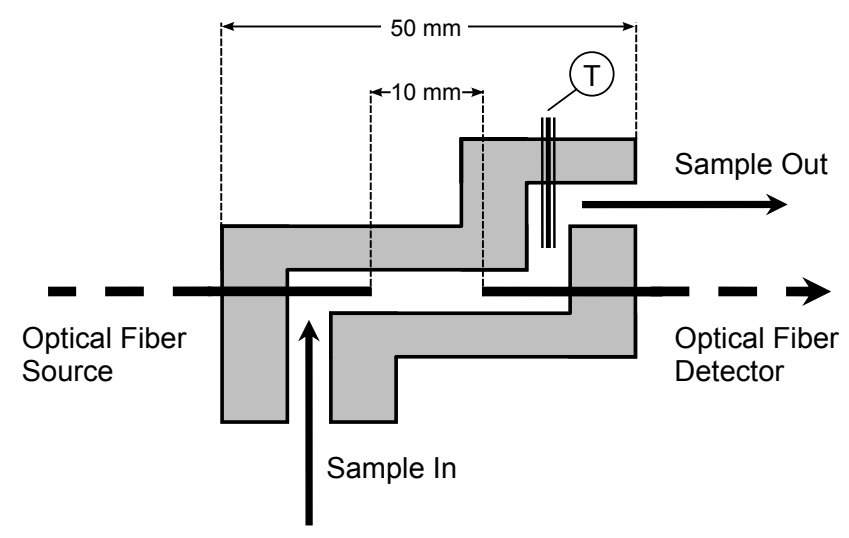

Fig. 2. Design of the custom made cuvette. The length of the optical path between the two fiber probes is $10 \mathrm{~mm}$. Each fiber has an overlap into the cuvette of $5 \mathrm{~mm}$ to minimize perturbations caused by air bubbles. $\mathrm{T}$ is a temperature sensor for direct sample measurements and temperature regulation of the sample.

has an internal volume of about $13 \mathrm{ml}$ of which the cuvette contains about $0.2 \mathrm{ml}$.

\subsection{Temperature control}

The temperature control of the sample flow is realized by means of a heat-exchange unit. Peltier elements are used to adjust the temperature of a custom-made aluminum body with an embedded steel tube. For temperature detection a calibrated temperature sensor (Jumo, Pt100 model PG 1.2812.1) is mounted in the cuvette. The temperature sensor is connected to a high precision signal amplifier and AD converter unit (Sea \& Sun, custom model). This combination was calibrated to an accuracy of better than $0.01^{\circ} \mathrm{C}$ using a freshly calibrated temperature reference sensor from Sea \& Sun (custom model). Peltier elements (Reichelt, TECB 3, rated power $=60 \mathrm{~W}$ ) excited by a programmable power supply (PeakTech, 1885) are used to provide the necessary heating or cooling. The necessary change of polarity is accomplished by a simple custom-made electronic circuit.

Once the sample flow is stable, the temperature fluctuation of the sample inside the cuvette was found to be $25^{\circ} \mathrm{C} \pm 0.006^{\circ} \mathrm{C}(1 \sigma)$. The temperature of the sample may be in the range of at least $0^{\circ} \mathrm{C} \leq T \leq 50^{\circ} \mathrm{C}$ without an impact on the stability of the temperature control. However, as the Peltier elements are cooled using the surrounding air and only working up to a certain temperature difference, the temperature of the surrounding air should be within $25^{\circ} \mathrm{C} \pm 25^{\circ} \mathrm{C}$. Data from a period of six days are shown in Fig. 3.

\subsection{Optical design}

For optical measurements an ultra-bright white LED (PerkinElmer, LED Fiber Optic Illuminator, OTFI-0100) with

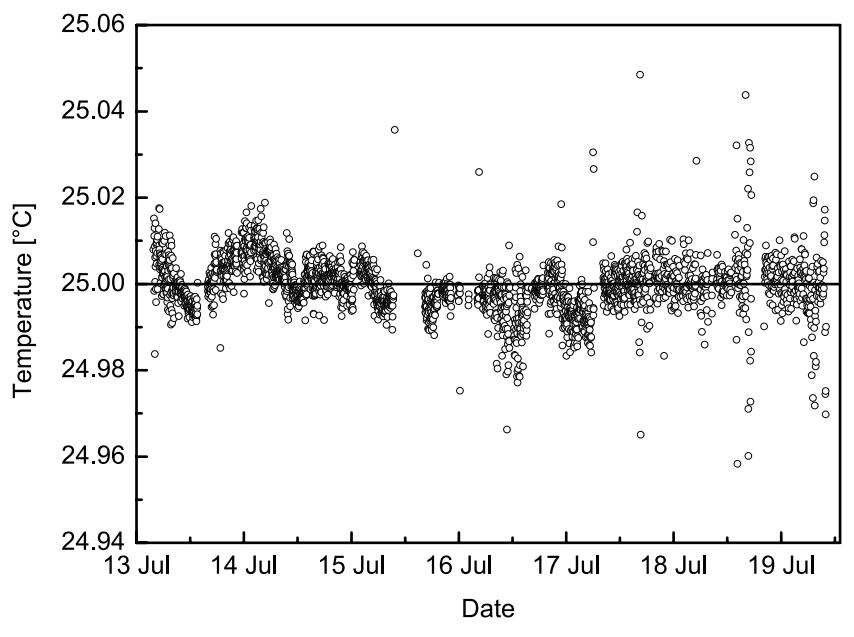

Fig. 3. Tightly controlled sample temperature at $25^{\circ} \mathrm{C} \pm 0.006^{\circ} \mathrm{C}$ detected in the cuvette which is a main criterion for precise $\mathrm{pH}$ measurements. Temperature regulation is realized by Peltier elements in a preceding heat exchanger (see Fig. 1). Data are from a six-day period during HE331 cruise in July 2010 on R/V Heincke.

a lifetime of $25000 \mathrm{~h}$ is used as light source. This light source has proven to be very stable. The long-term ( 3 days) drift amounts to approx. $2 \%$. The short-term $(15 \mathrm{~min})$ fluctuations are in the range of $\pm 0.1 \%$ (less than 20 counts). Due to the high stability a monitoring of the lamp intensity is redundant.

A 2048 pixel CCD spectrometer (Hamamatsu, C10082CAH) with a numerical aperture of 0.11 , a slit width of $10 \mu \mathrm{m}$ and a spectral response in the range between 200 and $800 \mathrm{~nm}$ is used as detector. The accuracy of the wavelength calculation polynomial and the optical resolution were determined in advance using a bench-top spectrometer (PerkinElmer, Lambda 950) in the laboratory. In contrast to CCD spectrometers from other manufacturers, a very good wavelength - pixel assignment and a spectral resolution of approx. $1 \mathrm{~nm}$ FWHM (Full Width Half Maximum) were determined over the entire spectrum.

Custom-engineered optical fibers from Ocean Optics ( $1 \mathrm{~m}$ length, $1000 \mu \mathrm{m}$ diameter optical fiber bundle) are used in this setup. The optical fibers reach about $5 \mathrm{~mm}$ into the optical path of the cuvette thus avoiding problems caused by air bubbles (Fig. 2). This is an important prerequisite for precise and accurate measurements (Martz et al., 2003).

\subsection{Electronics and software}

The entire setup was controlled by in house software written in the python programming language (van Rossum, 1995). It is based on software already described by Frank and Schroeder (2007). The software consists of three small programs and one slightly larger program which communicate with each other using network sockets. The small programs each communicate with one external device $(2 \times$ programmable power supply, $1 \times$ temperature unit, $1 \times$ 


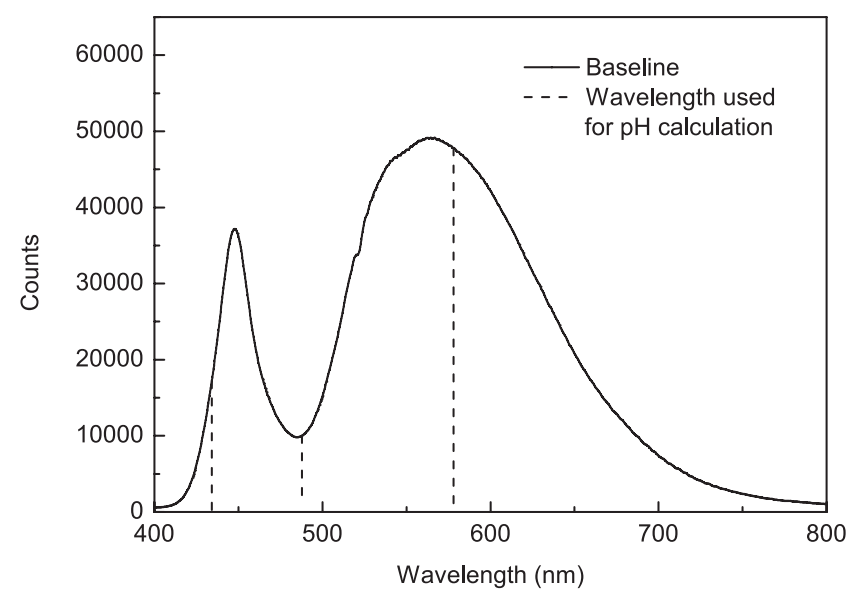

Fig. 4. Electrical counts of the emission spectrum of the ultra bright white LED taken with the CCD spectrometer during shipboard operation through seawater. The marked measurement wavelengths $434 \mathrm{~nm}$ and $578 \mathrm{~nm}$ are used for $\mathrm{pH}$ calculation and $487.6 \mathrm{~nm}$ (isosbestic point of $\mathrm{mCP}$ ) is used for detection of the indicator dye concentration.

custom-made electronic circuit) of which one also accounts for the temperature regulation of the heat exchanger. The main program controls the whole setup.

During data collection a precalculated $\mathrm{pH}$ value is estimated assuming a salinity of $S=35$. The final result is calculated later using the salinity measured either by an on-board thermosalinograph or the salinity data from the FerryBox. In the future on-line salinity and temperature data from the FerryBox will be used to directly calculate the final result.

\subsection{Calculation procedure}

A series of dark spectra is taken prior to every 100 measurement sequences and its average is subsequently subtracted from all other spectra. The dark spectrum only depends on the temperature of the CCD spectrometer's diode array which is held at constant temperature.

Even though the light source is very stable, a baseline spectrum was recorded prior to each measurement cycle to compensate for lamp aging as well as for changes of the optical properties of the seawater sample. Fifty baseline spectra are recorded and averaged simultaneously with the indicator injection into the sample flow. With an integration time of $10 \mathrm{~ms}$, recording the baseline takes less than a second. The spectrum of the lamp taken during shipboard operation is shown in Fig. 4.

For $\mathrm{pH}$ calculations three wavelengths are used. The $\mathrm{HI}^{-}$ and $\mathrm{I}^{2-}$ maxima are detected at $578 \mathrm{~nm}$ and $434 \mathrm{~nm}$ for calculating the $\mathrm{pH}$ value using Eq. (5). The isosbestic point detected at $487.6 \mathrm{~nm}$ is used for the correction of the perturbation of the seawater sample caused by the indicator injection.
After subtraction of the dark spectrum the three light intensities at the mentioned wavelengths are estimated from the raw data of the spectrometer. Therefore, a polynomial best-fit curve through the intensities of the adjacent pixels in the range of $\pm 10 \mathrm{~nm}$ around each of the three mentioned wavelengths is calculated. Interpolation due to the generated polynomial permits the calculation of the light intensity at the precise wavelength. This approach also compensates for electrical noise on the pixels of the CCD spectrometer.

Another important step of raw data treatment is the compensation of non-linearity of the CCD sensor as well as the 16 bit A/D converter inside the spectrometer for each pixel. The polynomial used to correct for this non-linearity was gained from experiments with the same spectrometer in advance. This was done by taking spectra at different integration times. As the light source is very stable the intensity should be directly proportional to the integration time. Any deviation from this behavior was used to generate the mentioned polynomial. The magnitude of the non-linearity increases with intensity. At 30000 counts an addition of 1044 counts is needed to maintain linearity. Hence, a correction for non-linearity is indispensable. Stray light inside the spectrometer which is compensated by this correction to a certain degree is neglected. Its maximum magnitude was found to be 50 counts resulting in a $\mathrm{pH}$ offset of less than -0.0004 units.

After these corrections the data can be used for the $\mathrm{pH}$ calculation procedure. The absorbance $\left(A_{\lambda}\right)$ calculation procedure is given in Eq. (7).

$A_{\lambda}=\log _{10}\left(\frac{I_{\lambda}^{0}}{I_{\lambda}}\right)$.

$I_{\lambda}$ and $I_{\lambda}^{0}$ are the intensities at the wavelength $\lambda$ of the sample and the baseline spectrum. No correction for baseline drift is necessary due to the high lamp stability and the high frequency of baseline measurements which take place prior to every indicator dye injection. Moreover, in this setup no significant intensities above $690 \mathrm{~nm}$ are available, because of the limitations in the spectrum of the lamp (see Fig. 4).

The influence of the addition of indicator solution on the sample $\mathrm{pH}$ can be estimated using different indicator concentrations (Clayton and Byrne, 1993; Zhang and Byrne, 1996). In this case an indicator concentration gradient is induced by the injection of a small amount (approx. $100 \mu \mathrm{l}$ ) of indicator stock solution by the indicator pump into the continuous sample flow, similar to Seidel et al. (2008). The concentration peak (Fig. 5) is moving through the cuvette and corresponding spectra are recorded. With an integration time of $10 \mathrm{~ms}$ more than 200 spectra are available for the indicator correction. The $\mathrm{pH}$ of each spectrum was calculated and a linear regression of $\mathrm{pH}$ vs. $A_{487.6}$ was performed (Fig. 6). During that process outliers caused by particles or air bubbles are removed. Every $\mathrm{pH}$ value with a residual larger than $6 \sigma_{\mathrm{e}}\left(\sigma_{\mathrm{e}}:\right.$ standard error of estimate of the linear regression) 


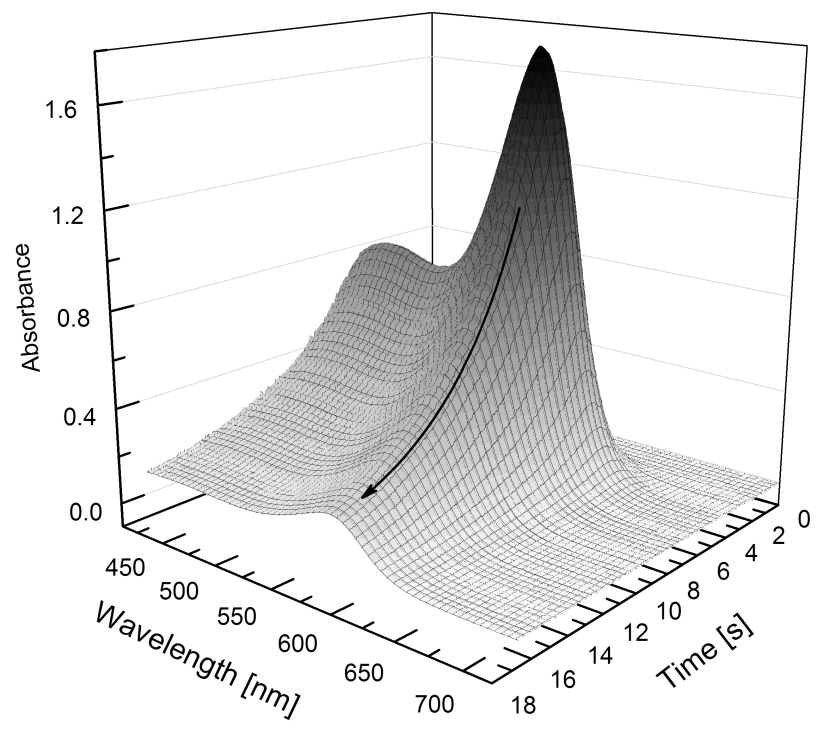

Fig. 5. Dilution curve passing the cuvette after indicator injection into a continuous sample flow and the recorded spectra. The smooth backward flank of the concentration peak is used for calculation of the perturbation-free $\mathrm{pH}$ value. For this more than 200 spectra are available (compare Fig. 6).

is removed which affects about $1 \%$ of the $\mathrm{pH}$ values during one indicator injection. The $\mathrm{pH}$ value can still be calculated with sufficient precision. The error of the perturbation-free $\mathrm{pH}$ value (axis intercept) during one measurement amounts to \pm 0.0002 ( $1 \sigma$ of intercept of linear regression of $\mathrm{pH}$ vs. $A_{487.6) \text {. }}$

The $\mathrm{pH}$ value of the indicator stock solution was roughly adjusted to $\mathrm{pH}_{\mathrm{NBS}}=8.2$ with $\mathrm{HCl} / \mathrm{NaOH}$ in the laboratory using a glass electrode to keep the perturbation of the seawater sample as small as possible. At a $\mathrm{pH}_{\mathrm{T}}=8.1067$ of the sample the perturbation amounts to up to $0.004 \mathrm{pH}$ units.

The final $\mathrm{pH}$ value is then converted from $25^{\circ} \mathrm{C}$ to in-situ temperature using R (R Development Core Team, 2011) and Seacarb (Lavigne and Gattuso, 2010). For this conversion the alkalinity is estimated from the salinity (Millero et al., 1998).

\section{Results and discussion}

\subsection{Measurement uncertainty}

\subsubsection{Precision}

The system described here is aimed for but not limited to integration into a well-established autonomous measurement system such as the FerryBox (Petersen et al., 2005). These autonomous systems are usually placed on platforms such as ships of opportunity, buoys, or on-shore stations. These measurement systems are usually serviced once a week or

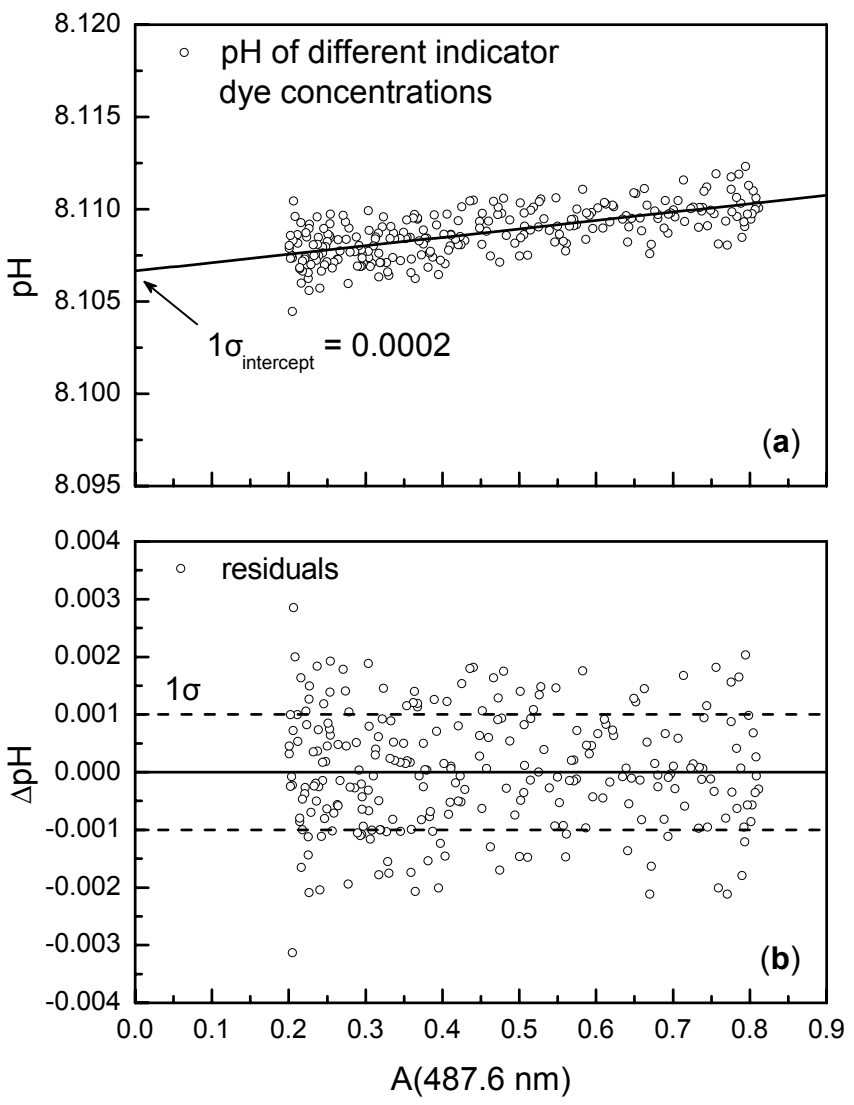

Fig. 6. Example plot for $\mathrm{pH}$ versus absorbance of $\mathrm{mCP}$ at $487.6 \mathrm{~nm}$. The curve in (a) represents a linear regression and extrapolation to zero indicator concentration. Slope $=0.0046 \pm 0.0003$; axis intercept $=8.1067 \pm 0.0002 ; N=258$. The residuals are given in (b). Errors are given as $1 \sigma$ standard error.

less. Under such conditions robustness and reliability are important prerequisites for all integrated and attached sensors and analyzers. Further requirements are portability, size, and weight of the device. These preconditions have an impact on the design of the system and therefore on its precision and accuracy. To estimate the system's precision and accuracy as well as its robustness, several tests have been carried out on board research vessels of which an excerpt is provided here.

The usual short-term precision detected on TRIS (2Amino-2-hydroxymethyl-propane-1,3-diol) buffers according to Dickson et al. (2007) was found to be $\pm 0.0007 \mathrm{pH}$ units (see Fig. 7). The long-term precision was not determined here but is expected to be less than $0.001 \mathrm{pH}$ units (Dickson, 1993). This could be assessed by frequent measurements of stable CRM buffers over several months. The precision for both short and long term is mainly generated by detector noise of the CCD spectrometer, errors in the measurement of the temperature in the cuvette, and vibration/bending of the fiber optics. 


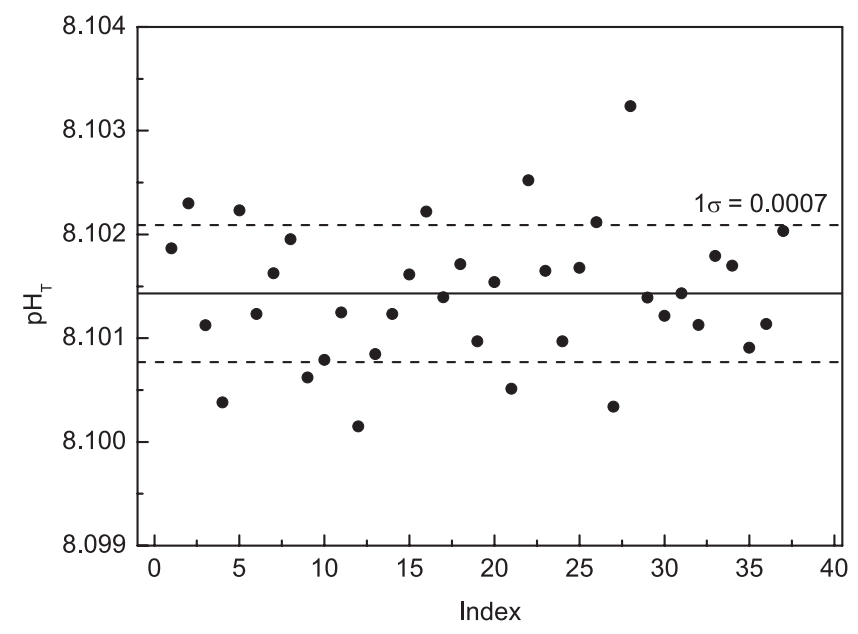

Fig. 7. Repetition measurements of a TRIS buffer based on the recipe in Dickson et al. (2007). The mean $\mathrm{pH}$ value is 8.1014 with a $1 \sigma$ standard deviation of $\pm 0.0007, N=37$. Index is the consecutive number of the repetition measurements.

\subsubsection{Accuracy}

To determine the accuracy of the system, a TRIS buffer provided by Scripps Institution of Oceanography in La Jolla/California (Batch 6: $\mathrm{pH}=8.0893 \pm 0.0009$ ) was used as CRM. Comparative measurements were made with a bench-top spectrometer (PerkinElmer, Lambda 950) in the laboratory where the $\mathrm{pH}$ of the CRM was found to be $8.0969 \pm 0.0004 \mathrm{pH}$ units. The measured $\mathrm{pH}$ using the underway $\mathrm{pH}$-system was found to be $8.0974 \pm 0.0006$. The average offset of the underway system compared to the benchtop spectrometer is $+0.0005 \mathrm{pH}$ units. The offset to the CRM amounts to $+0.0081 \mathrm{pH}$ units.

The accuracy of $+0.0081 \mathrm{pH}$ units at $\mathrm{pH}=8.0893 \pm$ 0.0009 is caused by a number of factors. Impurities in the indicator dye which can cause offsets of up to $0.01 \mathrm{pH}$ units (Yao et al., 2007) is most likely the determining factor. In addition the magnitude of this error depends on the $\mathrm{pH}$ value. This affects the previously found equilibrium constant and extinction coefficients by Clayton and Byrne (1993) but can be solved if the dye is purified and new constants are applied (Liu et al., 2011). The calibration of the temperature sensor has an accuracy of $<0.01^{\circ} \mathrm{C}$ resulting in an error of approx. $\pm 0.0002 \mathrm{pH}$ units. Additional issues can be found in the linearity correction of the CCD spectrometer which amounts to approx. 50 counts resulting in $\pm 0.0004 \mathrm{pH}$ units. Stray light in the spectrometer contributes to an error of approx. $-0.0004 \mathrm{pH}$ units as discussed above. Fluctuations of the light source ( 20 counts in $15 \mathrm{~min}$ ) may cause errors of less than $\pm 0.0002 \mathrm{pH}$ units.

Bench-top spectrometry is used as the reference method, because a well specified standard operating procedure exists (Dickson et al., 2007, SOP 6b). This reference system was used to assess the indicator independent error of the underway system. However, concerning the offset of $+0.0005 \mathrm{pH}$ units there are some points that have to be mentioned. Although the measurement principle is the same, the sample handling is quite different. The bench-top system uses discrete samples and only a few points (at least two) for correction of the indicator perturbation. It takes some time for one $\mathrm{pH}$ determination (at least $5 \mathrm{~min}$ ) while the underway system takes at most 1 min. Thus, the uptake of $\mathrm{CO}_{2}$ from the surrounding atmosphere can change the $\mathrm{pH}$ of the sample during one $\mathrm{pH}$ determination with the bench-top system. In contrast, the underway system uses flow injection analysis (FIA) which is highly reproducible. Hence, any changes in the sample due to changes in the environment (e.g. air $\mathrm{CO}_{2}$ concentration) will change all parts of the sample in the same way. A small error might be generated by the PTFE tubing used in this setup which is not absolutely gas tight. The reproducibility of the FIA system is therefore a very large advantage compared to the sample handling with the bench-top system. Another difference is given by the temperature control of the bench-top system. Here, the temperature is only assured to be $25^{\circ} \mathrm{C} \pm 0.1{ }^{\circ} \mathrm{C}$ while the underway system is much more stable (see Sect. 3.2). Stray light in the spectrometer changing with indicator concentration/light intensity only occurs with the underway system. Nevertheless, the offset to the bench-top spectrometer is expected to be within \pm 0.0012 over the whole indicator range which is the sum of all aforementioned accuracy errors, except the error caused by the indicator dye.

For a comprehensive evaluation of accuracy of this system additional carbon system parameters such as total dissolved inorganic carbon (DIC), total alkalinity (TA), or $\mathrm{CO}_{2}$ fugacity $\left(f \mathrm{CO}_{2}\right)$ are required to obtain an overdetermined system for cross validation. Wang et al. (2007) has introduced such a system with three carbon parameters achieving a good internal consistency.

\subsection{Underway measurements}

Underway measurements were performed during the R/V Polarstern cruises ANT-XXVI/1 (November 2009) and ANTXXVI/4 (May 2010) over periods of six weeks each as well as on several shorter cruises of approx. six to ten days in the North Sea (August 2009, July 2010, September 2010). During these cruises, the system was further optimized and tested. One continuous dataset from 13 to 19 July 2010 generated in the North Sea is presented in Fig. 8. During that period of continuous operation more than 3000 measurements were carried out at a rate of about $1.5 \mathrm{~min}^{-1}$. The program was only interrupted during cleaning cycles of the FerryBox (once a day) and for validation measurements. The FerryBox system provides flow rates of $141 \mathrm{~min}^{-1}$ and measures at near to in-situ conditions. A slight temperature uncertainty of $\pm 0.2^{\circ} \mathrm{C}$ has to be considered because the sample water 


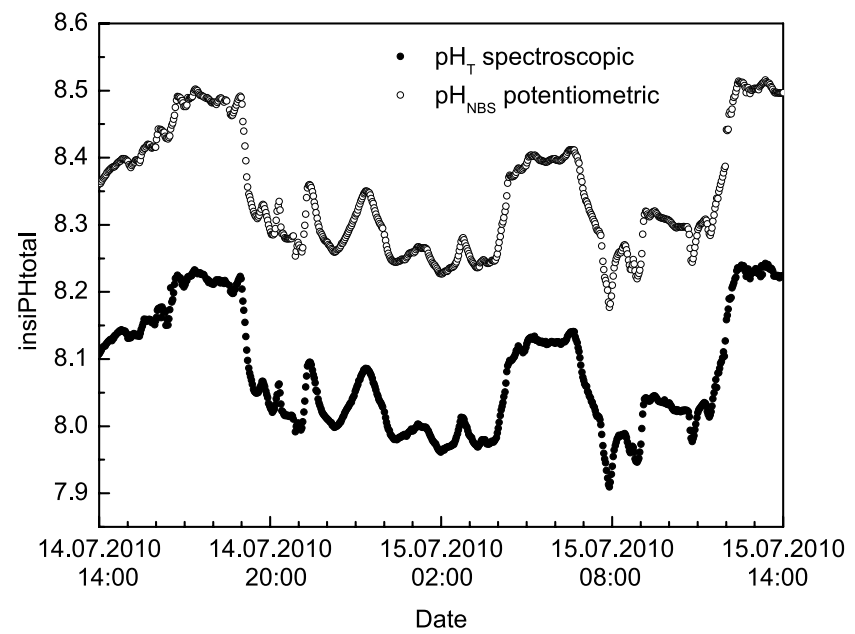

Fig. 8. Comparison of the optically (total scale) and potentiometrically (NBS scale) measured $\mathrm{pH}$ values for a selected period of $24 \mathrm{~h}$ with intense $\mathrm{pH}$ variations. $\mathrm{pH}$ values at NBS scale are measured at in-situ temperature, while $\mathrm{pH}$ values at total scale are converted to in-situ temperature. The average offset is $0.27 \mathrm{pH}$ units. The last calibration of the glass electrode up to that point was more than a week earlier.

passes $6 \mathrm{~m}$ of tubing $(30 \mathrm{~mm}$ i.d.) before entering the measuring system.

All $\mathrm{pH}$ values exceeding an error of $\pm 0.0005 \mathrm{pH}$ units during the correction for indicator perturbation are discarded. This affects approx. $5 \%$ of the data. These higher errors are mainly caused by high temperature fluctuations of the sample due to interruptions of the sample flow, air bubbles, or sediment load. With this filter nearly all outliers are eliminated. If the water supply is more stable, the amount of outliers could be reduced to less than $1 \%$.

For comparison purposes the $\mathrm{pH}$ data of this system are plotted along with FerryBox data generated by a glass electrode. The glass electrode was chosen because it is a part of the flow through system of the FerryBox. Up to now it is the only operational commercially available system suitable for FerryBox integration. The comparison is however limited to qualitative aspects as the accuracy and stability of these electrodes is very limited. Here, only a period of $24 \mathrm{~h}$ is plotted to avoid an excessively complex graph (Fig. 8). This graph provides a first overview of the behavior of the sensor such as a high peak/gradient resolution.

The glass electrode is calibrated once every seven days during a cruise using standard NBS buffers at $\mathrm{pH} 7$ and 9 (Metrohm, Germany). In Fig. 9b on 16 July there is a step in the differences between both $\mathrm{pH}$ traces indicating such a calibration point. It has to be mentioned that the previous calibration of the electrode was made more than one week prior to this. This step illustrates the problems connected to potentiometric $\mathrm{pH}$ measurements such as liquid junction drift or problems with the reference electrode.

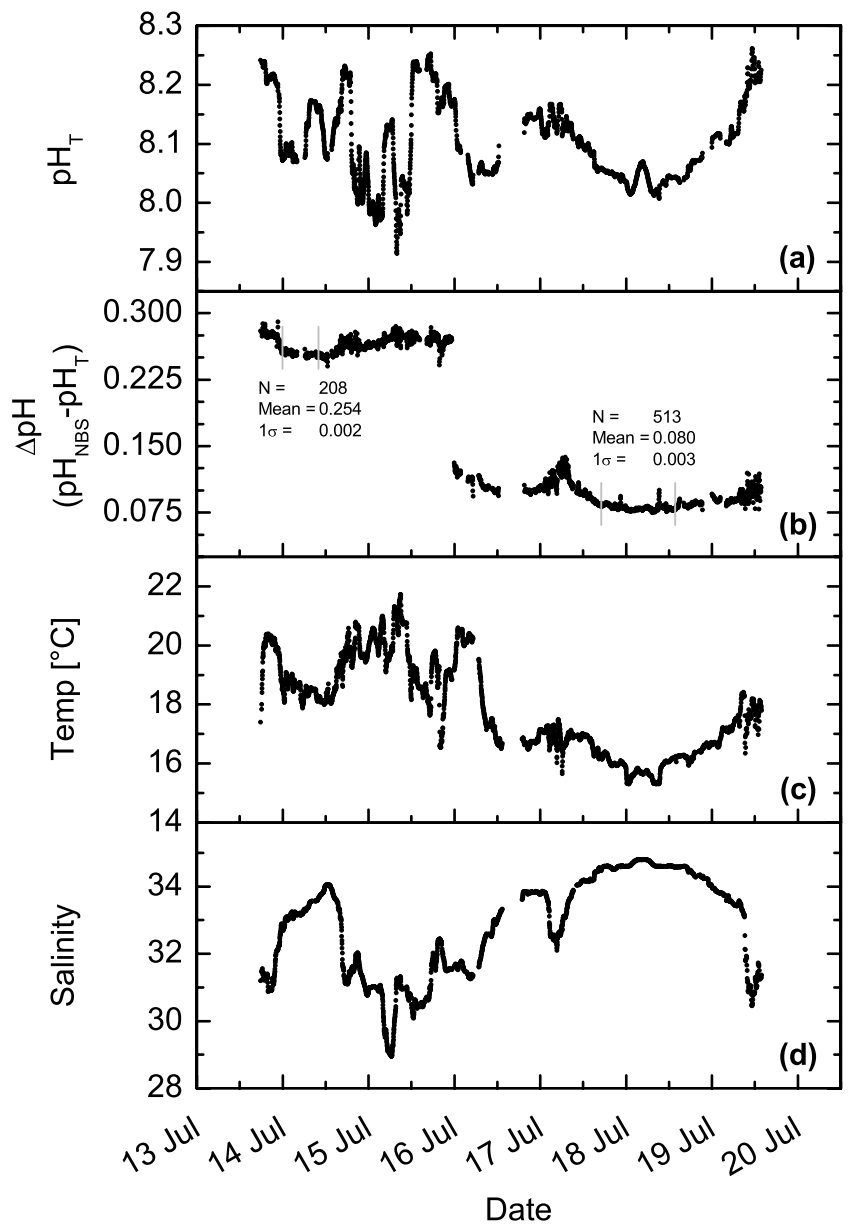

Fig. 9. In-situ data of a cruise in the North Sea from 13 to 19 July 2010. (a) Optically measured $\mathrm{pH}_{\mathrm{T}}$. (b) Differences of potentiometric and spectrophotometric measured $\mathrm{pH}$. A calibration of the glass electrode took place at 16 July. Before and after the calibration point, there are two sectors marked with low variations of $S$ and $T$. Mean and standard deviation are calculated for these regions. (c) Temperature measured in the FerryBox. (d) Salinity measured in the FerryBox.

Figure 9 provides an overview of the $\mathrm{pH}$ measurements during a six day cruise in the North Sea and shows the high variability in this area. The high variability is caused by nutrient rich water bodies, primary production, respiration, tidal cycles, and the fresh water impact of rivers. Both sensors show a very similar behavior over the whole range of temperatures ( 15 to $21^{\circ} \mathrm{C}$, Fig. 9c) and salinities (29 to 35, Fig. 9d) during these seven days. There are two larger variations in the differences of the two sensors on 17 July and at the very end of the cruise due to problems with the water sample supply. During the time from 17 to 19 July the distribution of the differences are smaller than before (i.e. 14 to 17 July) due to lower $\mathrm{pH}$ gradients during this period. This can be explained with slight mismatches in time which could not be fully eliminated as well as by a slightly different time 
constant of the sensors themselves. Hence, higher gradients in the water composition lead to higher differences between the sensors.

The structure in the offset between potentiometric and optical $\mathrm{pH}$ determination (e.g. the decrease in offset on 13 July and the peak on 17 July) is caused by the changes in seawater salinity and temperature. When varying $S$ and $T$ the measurement of the activity $a_{\mathrm{H}^{+}}$using a glass electrode is affected in a different manner than the measurement of $\left[\mathrm{H}^{+}\right]_{\mathrm{T}}$ using a spectrophotometric sensor. The activity coefficients are increasing with increasing $S$ and decreasing with increasing $T$. The outcome of this is the inverse behavior in the differences of the two pH scales (Fig. 9b).

Furthermore, there is a slight drift of the $\mathrm{pH}$ electrode from 16 to 20 July which can be explained with changes in the structure of the glass membrane due to aging and fouling. These changes are unavoidable with the present commercially available systems. The presented data show that a combination of a glass electrode with an indicator based optical system may be even better suited for highly dynamic systems like the North Sea and its coast. It has been shown that a glass electrode can be stable for at most one day (Tishchenko et al., 2011) and needs to be calibrated according to this time range, e.g. using an optical system. This leads to lower indicator consumption for long-term deployments without losing any temporal information. Moreover, the electrode data is more reliable outside of the $\mathrm{pH}$ range of $\mathrm{mCP}(7.4 \leq \mathrm{pH} \leq 9.0)$ as well as in salinities and temperatures outside the range of the specified correction functions of mCP with $5^{\circ} \mathrm{C} \leq T \leq 35^{\circ} \mathrm{C}$ and $20 \leq S \leq 40$ for purified $\mathrm{mCP}$ (Liu et al., 2011) or $20^{\circ} \mathrm{C} \leq T \leq 30^{\circ} \mathrm{C}$ and $30 \leq S \leq 37$ for impure mCP (Clayton and Byrne, 1993), respectively.

\subsection{Size and cost}

No attempt was made to further optimize the system size. Nevertheless, the presented system is very portable and much smaller than comparable systems with similar features (e.g. Friis et al., 2004). No water bath is needed, which reduces all related problems like size and handling. The whole system consists of three units not including the computer. The fluid handling system has a volume of 131 , the electronics box (including the spectrometer) is about 91, and the two programmable power supplies have a combined volume of 91 . For integration into an automated water measurement system some simple size optimization would lead to a system about half that size.

While the components of the system add up to total costs of about $8000 €$ including the mini spectrometer (4000€), syringe pump $(300 €)$, peristaltic pump $(1400 €)$, electronics for temperature control (1200€), computer and miscellaneous components $(1100 €)$, the running costs are low. Only one temperature sensor has to be calibrated. All other values are relative and do not require calibration. Maintenance consists of changing the syringes (once during a R/V Po- larstern cruise of six weeks), refilling the indicator solution (1.51 lasts for more than six weeks at a measurement frequency of $4 \mathrm{~min}^{-1}$ ), and cleaning the cuvette (once every six weeks).

A more extensive account of expense budgeting is beyond the scope of this article. The costs given above are those for building a replicate as a researcher, not as a manufacturer.

\subsection{Reliability}

The system was optimized during several cruises in the North Sea as well as in the Atlantic Ocean. The addition of the check valve was a minor but extremely important improvement for the stability of the $\mathrm{pH}$ determination. The system was very stable during all cruises. Air bubbles in the optical path cause problems and affect the precision of the result but do not change the $\mathrm{pH}$ value itself.

Spectral changes in the sample are compensated by the blank measurements prior to each injection. It is assumed that the sample does not change significantly during one measurement routine of less than $1 \mathrm{~min}$. Optical changes due to light scattering caused by particles are thus only caused by the dye itself. These can be eliminated by filtering the stock solution using a filter with a pore size less than $0.4 \mu \mathrm{m}$. As a result no drift of the baseline occurs and a drift correction at a non-absorbing wavelength can be omitted.

Another issue which has to be accounted for is fouling. The fouling actually only has an effect on the intensity of light which reaches the detector and therefore it does not change the result of the measurement. However, it has an impact on the precision. All FerryBox systems have a cleaning procedure which is performed at least once a day. A first step is rinsing the whole system with fresh water. Afterwards sulfuric acid is added up to $\mathrm{pH}=2$, and finally oxalic acid is added into another fresh-water cleaning cycle to clean up oxidation products such as from the corrosion of steel. This cleaning cycle also cleans the whole fluid path of the $\mathrm{pH}$ analyzer which also includes the optical path. No further cleaning procedures are necessary.

\section{Conclusions}

It has been shown that it is possible to build a small, robust, and autonomous $\mathrm{pH}$ sensor in state-of-the-art $\mathrm{CO}_{2}$-system quality which is suitable for integration into automated seawater measurement systems. The instrument described here reaches a precision of $\pm 0.0007 \mathrm{pH}$ units with a measurement frequency of up to $1 \mathrm{~min}^{-1}$. The accuracy is $0.0081 \mathrm{pH}$ units compared to CRM and $0.0005 \mathrm{pH}$ units to a reference system.

The method used to adjust the sample temperature to $25^{\circ} \mathrm{C} \pm 0.006^{\circ} \mathrm{C}$ is sophisticated but not complex and the whole system has proved to work reliably on ships. The integration into automated water measurement systems has been accomplished and provisions have been made for more 
demanding conditions, for example in the engine room of a ship.

The system has proven to be stable, reliable and accurate during all tests on board research vessels. With these characteristics this device is ready to be used in combination with analyzers for dissolved inorganic carbon (DIC) or total alkalinity (TA) for a comprehensive characterization of the seawater carbon system.

Acknowledgements. This work was supported by the project OCEANET of the WGL Leibniz Association. We thank Friedhelm Schroeder who made this collaboration possible at the HelmholtzZentrum Geesthacht. Martina Gehrung provided FerryBox data, such as in-situ salinity and temperature. We thank Peer Fietzek and Björn Fiedler for helpful discussions within the working group and Rüdiger Röttgers for providing his lab for spectrophotometric measurements. Special thanks belong to Karsten Friis, who gave precious advice especially in the early stages of this work.

Edited by: C. Robinson

\section{References}

Bellerby, R. G. J., Olsen, A., Johannessen, T., and Croot, P.: A high precision spectrophotometric method for on-line shipboard seawater $\mathrm{pH}$ measurements: the automated marine pH sensor (AMpS), Talanta, 56, 61-69, doi:10.1016/S00399140(01)00541-0, 2002.

Clayton, T. D. and Byrne, R. H.: Spectrophotometric seawater pH measurements: total hydrogen ion concentration scale calibration of m-cresol purple and at-sea results, Deep-Sea Res. Pt. I, 40, 2115-2129, doi:10.1016/0967-0637(93)90048-8, 1993.

DelValls, T. A. and Dickson, A. G.: The pH of buffers based on 2amino-2-hydroxymethyl-1,3-propanediol ("tris") in synthetic sea water, Deep-Sea Res. Pt. I, 45, 1541-1554, doi:10.1016/S09670637(98)00019-3, 1998.

Dickson, A. G.: $\mathrm{pH}$ scales and proton-transfer reactions in saline media such as sea water, Geochim. Cosmochim. Ac., 48, 22992308, doi:10.1016/0016-7037(84)90225-4, 1984.

Dickson, A. G.: The measurement of sea water pH, Mar. Chem., 44, 131-142, doi:10.1016/0304-4203(93)90198-W, 1993.

Dickson, A. G., Sabine, C. L., and Christian, J. R.: Guide to best practices for ocean $\mathrm{CO}_{2}$ measurements, PICES Special Publication 3, 191 pp., 2007.

Doney, S. C., Fabry, V. J., Feely, R. A., and Kleypas, J. A.: Ocean acidification: the other $\mathrm{CO}_{2}$ problem, Annual Review of Marine Science, 1, 169-192, doi:10.1146/annurev.marine.010908.163834, 2009.

Dore, J. E., Lukas, R., Sadler, D. W., Church, M. J., and Karl, D. M.: Physical and biogeochemical modulation of ocean acidification in the central North Pacific., Proc. Natl. Acad. Sci. USA, 106, 12235-12240, doi:10.1073/pnas.0906044106, 2009.

Fabry, V. J., Seibel, B. a., Feely, R. a., and Orr, J. C.: Impacts of ocean acidification on marine fauna and ecosystem processes, ICES J. Mar. Sci., 65, 414-432, doi:10.1093/icesjms/fsn048, 2008.

Feely, R. A., Doney, S. C., and Cooley, S. R.: Ocean acidification: Present conditions and future changes in a high- $\mathrm{CO}_{2}$ world,
Oceanography, 22, 36-47, doi:10.1371/journal.pone.0022736, 2009.

Frank, C. and Schroeder, F.: Using Sequential Injection Analysis to Improve System and Data Reliability of Online Methods: Determination of Ammonium and Phosphate in Coastal Waters, J. Autom. Method. Manag., 2007, 49535, doi:10.1155/2007/49535, 2007.

Friis, K., Körtzinger, A., and Wallace, D. W. R.: Spectrophotometric $\mathrm{pH}$ measurement in the ocean: Requirements, design, and testing of an autonomous charge-coupled device detector system, Limnol. Oceanogr.-Meth., 2, 126-136, doi:10.4319/lom.2004.2.126, 2004.

Lavigne, H. and Gattuso, J. P.: seacarb: seawater carbonate chemistry with R. R package version 2.3. 3, Software, 2010.

Liu, X., Wang, Z. A., Byrne, R. H., Kaltenbacher, E. A., and Bernstein, R. E.: Spectrophotometric Measurements of $\mathrm{pH}$ in-Situ: Laboratory and Field Evaluations of Instrumental Performance, Environ. Sci. Technol., 40, 5036-5044, doi:10.1021/es0601843, 2006.

Liu, X., Patsavas, M. C., and Byrne, R. H.: Purification and Characterization of meta-Cresol Purple for Spectrophotometric Seawater pH Measurements, Environ. Sci. Technol., 45, 4862-4868, doi:10.1021/es200665d, 2011.

Martz, T. R., Carr, J. J., French, C. R., and DeGrandpre, M. D.: A Submersible Autonomous Sensor for Spectrophotometric $\mathrm{pH}$ Measurements of Natural Waters, Anal. Chem., 75, 1844-1850, doi:10.1021/ac0205681, 2003.

Martz, T. R., Connery, J. G., and Johnson, K. S.: Testing the Honeywell Durafet for seawater $\mathrm{pH}$ applications, Limnol. Oceanogr.Meth., 8, 172-184, doi:10.4319/lom.2010.8.172, 2010.

Millero, F. J.: The marine inorganic carbon cycle., Chemical reviews, 107, 308-41, doi:10.1021/cr0503557, 2007.

Millero, F. J., Lee, K., and Roche, M.: Distribution of alkalinity in the surface waters of the major oceans, Mar. Chem., 60, 111-130, doi:10.1016/S0304-4203(97)00084-4, 1998.

Milne, G. W. A.: Gardner's commercially important chemicals: synonyms, trade names, and properties, Wiley, doi:10.1002/0471736627.ch1, 2005.

Nakano, Y., Kimoto, H., Watanabe, S., Harada, K., and Watanabe, Y. W.: Simultaneous vertical measurements of in situ $\mathrm{pH}$ and $\mathrm{CO}_{2}$ in the sea using spectrophotometric profilers, J. Oceanogr., 62, 71-81, doi:10.1007/s10872-006-0033-y, 2006.

Petersen, W., Petschatnikov, M., Schroeder, F., and Colijn, F.: FerryBox systems for monitoring coastal waters, Elsev. Oceanogr. Serie., 69, 325-333, doi:10.1016/S04229894(03)80052-1, 2003.

Petersen, W., Petschatnikov, M., Wehde, H., and Schroeder, F.: FerryBox- Real-Time Monitoring of Water Quality by Ferryboats, Environmental Research, Engineering and Management, 3, 12-17, 2005.

R Development Core Team: R: A Language and Environment for Statistical Computing, 2011.

Raven, J., Caldeira, K., Elderfield, H., Hough-Guldberg, O., Liss, P., Riebesell, U., Shepherd, J., Turley, C. M., and Watson, A.: Ocean acidification due to previous termincreasing atmospheric carbon dioxide, The Royal Society Policy Document, 12, 68 pp., 2005.

Sabine, C. L. and Tanhua, T.: Estimation of Anthropogenic $\mathrm{CO}_{2}$ Inventories in the Ocean, Annual Review of Marine Science, 2, 
175-198, doi:10.1146/annurev-marine-120308-080947, 2010.

Sabine, C. L., Feely, R. A., Gruber, N., Key, R. M., Lee, K., Bullister, J. L., Wanninkhof, R., Wong, C. S., Wallace, D. W. R., Tilbrook, B., Millero, F. J., Peng, T.-H., Kozyr, A., Ono, T., and Rios, A. F.: The oceanic sink for anthropogenic $\mathrm{CO}_{2}$., Science, 305, 367-371, doi:10.1126/science.1097403, 2004.

Salim, S. G. R., Fox, N. P., Theocharous, E., Sun, T., and Grattan, K. T. V.: Temperature and nonlinearity corrections for a photodiode array spectrometer used in the field, Appl. Optics, 50, 866-875, doi:10.1364/AO.50.000866, 2011.

SCOR Working Group 75: Methodology for oceanic $\mathrm{CO}_{2}$ measurements, Unesco technical papers in marine science, 65, 44 pp., 1988.

Seidel, M. P., DeGrandpre, M. D., and Dickson, A. G.: A sensor for in situ indicator-based measurements of seawater $\mathrm{pH}$, Mar. Chem., 109, 18-28, doi:10.1016/j.marchem.2007.11.013, 2008.

Tishchenko, P. Y., Kang, D. J., Chichkin, R. V., Lazaryuk, A. Y., Shing Wong, C., and Keith Johnson, W.: Application of potentiometric method using a cell without liquid junction to underway $\mathrm{pH}$ measurements in surface seawater, Deep-Sea Res. Pt. I, 58, 778-786, doi:10.1016/j.dsr.2011.05.002, 2011. van Rossum, G.: Python library reference, Citeseer, Amsterdam, 2 edn., 1995.

Wang, Z. A., Liu, X., Byrne, R. H., Wanninkhof, R., Bernstein, R. E., Kaltenbacher, E. A., and Patten, J.: Simultaneous spectrophotometric flow-through measurements of $\mathrm{pH}$, carbon dioxide fugacity, and total inorganic carbon in seawater, Anal. Chim. Acta, 596, 23-36, doi:10.1016/j.aca.2007.05.048, 2007.

Yao, W., Liu, X., and Byrne, R. H.: Impurities in indicators used for spectrophotometric seawater $\mathrm{pH}$ measurements: Assessment and remedies, Mar. Chem., 107, 167-172, doi:10.1016/j.marchem.2007.06.012, 2007.

Zeebe, R. E. and Wolf-Gladrow, D. A.: $\mathrm{CO}_{2}$ in seawater: equilibrium, kinetics, isotopes, vol. 65, Elsevier Science, 2001.

Zhang, H. and Byrne, R. H.: Spectrophotometric pH measurements of surface seawater at in-situ conditions: absorbance and protonation behavior of thymol blue, Mar. Chem., 52, 17-25, doi:10.1016/0304-4203(95)00076-3, 1996. 